Brit. J. prev. soc. Med. (1975), 29, 190-195

\title{
The role of driver demerit points and age in the prediction of motor vehicle collisions
}

\author{
M. L. CHIPMAN AND PETER MORGAN \\ Department of Preventive Medicine, University of Toronto
}

\begin{abstract}
Chipman, M. L. and Morgan, P. (1975). British Journal of Preventive and Social Medicine, 29, 190-195. The role of driver demerit points and age in the prediction of motor vehicle collisions. The records of drivers, selected from the file of licensed drivers in Ontario, were reviewed to study the relationship between demerit points, other driver characteristics, and the frequency or risk of future collisions and traffic convictions. A stratified sample of 500-600 drivers from each of five levels of demerit points was selected. Low-point drivers differed significantly from high-point drivers in age, sex, and class of licence; estimates of risk of collision or conviction in each demerit point group had to take account of these differences. Discriminant analysis was used to identify drivers likely to be involved in collisions or to be given traffic convictions, and to identify accidents involving injury or fatality. Of the traits considered (demerit points, age, sex, class of licence, history of previous accidents), demerit points represented the only variable of importance in predicting future collision involvement. Since it is the only one of these variables which can be altered by driver behaviour it offers an opportunity to prevent accidents.
\end{abstract}

Once they have passed the driving test, few drivers have their driving skills assessed except by the subjective opinions of fellow motorists and through receiving traffic tickets. The latter may lead to disciplinary action in the form of fines and, for multiple offences, to suspension of driving privileges. In order to administer such suspensions in a fair and systematic way, systems of demerit points have been developed in many parts of North America and in some countries in Europe. Points are assigned to each driver based on the number and type of convictions for traffic offences he has recently committed. In Ontario, for example, each of 26 traffic violations has been assigned a number of points depending on the presumed severity of the offence. Values range from seven points for 'failure to remain at the scene of an accident' to two points for 'unnecessarily slow driving'. Drivers who accumulate 15 or more points in a two year period lose their licences for periods of one to six months.

Several studies have shown that traffic offences indicate one's risk of collision. Brezina (1969)

Project funded by Traffic Injury Research Foundation of Canada, Inc. Dr Morgan is supported by National Health Grant No. 605-7-746. found an association between convictions for speeding and subsequent accident occurrence in Ontario. He also reported that characteristics such as age, sex, and size of urban settlement influenced both accident and violation frequencies but did not include these variables when relating accidents to the type of offence. The association between offences and accidents may thus be explained by these common factors. Drivers involved in pedestrian fatalities and single car crashes have been found to have substantially more previous traffic offences than control groups (Baker, Robertson, and O'Neill, 1974; and Schmidt et al., 1972).

There are several reasons why traffic convictions should not be good predictors of subsequent collision. First, the actions of the driver leading up to a collision or a conviction may be quite different. One study which tested reaction time and other behaviour in drivers demonstrated that those who had had many convictions but had never had an accident performed significantly better than drivers who had a record of at least one collision but no convictions (Fergenson, 1971). Secondly, it is often difficult to identify the violation which 'caused' a 
specific accident (Zylman, 1972). Thirdly, the accumulation of convictions and the occurrence of collisions are not necessarily related to the same exposure factors. For example, the intensity of police surveillance in the neighbourhood affects the driver's frequency of conviction but may have little influence on his risk of collision.

The occurrence of traffic convictions is thus subject to many factors which should weaken its ability to predict subsequent traffic accidents. Nevertheless it is often assumed that frequent traffic convictions, as measured by an accumulation of demerit points, indicate poor driving ability and that bad drivers have more collisions. We wish to examine these assumptions in the light of other factors which are associated with both risk of accident and frequency of traffic violations: age, sex, class of licence, and history of previous collision involvement.

\section{METHODS}

We obtained information from the records of 2650 unidentified licensed drivers from the Ministry of Transportation and Communication in Ontario. Beginning in July 1966, a computer file of driver records was established; drivers were entered in the file either when they renewed their licence for the next three years, when a new licence was granted, or if the driver was involved in an accident or traffic offence. Each driver had a record covering an average of 2.5 years before July 1970 and a further $2 \cdot 5$ years from July 1970 to December 1972.

Drivers were selected for our study according to the number of demerit points outstanding on 1 July 1970. As shown in Table I, there were 3.5 million drivers in Ontario in 1970; $85 \%$ had two or fewer demerit points; only $0.3 \%$ had 12 or more points. In order to have an adequate number of drivers with large numbers of points we used a stratified sample, choosing 500 to 600 drivers from each of five levels

TABLE I

DISTRIBUTION OF DRIVERS BY DEMERIT POINTS 1 JULY 1970

\begin{tabular}{c|c|c}
\hline Demerit Points & Percent of all Drivers* & Size of Sample \\
\hline $0-2$ & $85 \cdot 3$ & 591 \\
$3-5$ & $11 \cdot 1$ & 531 \\
$6-8$ & $2 \cdot 7$ & 511 \\
$9-11$ & $0 \cdot 6$ & 486 \\
$12+$ & $0 \cdot 3$ & 531 \\
\hline & & 2650 \\
\hline
\end{tabular}

* Total drivers $=3.5$ million of demerit points by systematic sampling. One in 5000 drivers in the 0-2 point stratum up to one in 17 drivers in the 12 or more points stratum were selected in this way for a total of 2650 drivers.

The number of drivers chosen in each stratum was sufficient to describe most variables adequately. One notable exception was the variable sex: women were very infrequent in the high-point strata, and some analyses were confined to male drivers only. We examined the age, sex, and class of licence of the drivers in each stratum and calculated the risk of collision or traffic convictions in the period July 1970 to December 1972 for each level of demerit points. Because substantial differences in age, sex, and class of licence existed between drivers in each stratum, these factors were accounted for by the use of specific or standardized rates.

We identified those drivers who, from their demerit points, age, sex, and other traits, appeared likely to be involved in collisions or further traffic violations by calculating a discriminant function based on these data. Three different classifications were attempted:

1. drivers with one or more convictions and drivers with no convictions after 1 July 1970;

2. drivers with one or more collisions and drivers with no collisions after 1 July 1970;

3. for each collision, collisions resulting in personal injury or death and those resulting only in property damage.

The variables studied for their ability to discriminate between these groups were those used in the earlier calculations (age, sex, class of licence; and demerit points) and one additional variable, history of a collision occurring before 1 July 1970 . The calculations for discriminant analysis were carried out with the help of the BMD Biomedical Computer Program BMD07M (Dixon, 1973). This program is a stepwise procedure: the variable with the greatest power to discriminate is used first in the analysis, followed by each variable which can contribute the most additional discrimination. The proportion of correct classifications, as 'collisionfree' or 'conviction-free' for example, was then calculated as a measure of discriminatory power.

\section{RESULTS}

The average number of convictions and collisions, and the risk of involvement in at least one collision increased fairly steadily as demerit points increased (Table II). The mean number of convictions rose from 0.53 in the lowest stratum to 2.73 in the highest. Similarly the mean number of collisions 
TABLE II

EXPERIENCE OF DRIVERS AFTER 1 JULY 1970

\begin{tabular}{c|c|c|c}
\hline $\begin{array}{c}\text { Demerit } \\
\text { Points }\end{array}$ & $\begin{array}{c}\text { Mean No. } \\
\text { of Convictions }\end{array}$ & $\begin{array}{c}\text { Mean No. } \\
\text { of Collisions }\end{array}$ & $\begin{array}{c}\text { Drivers with One } \\
\text { or More Collisions } \\
(\%)\end{array}$ \\
\hline $0-2$ & 0.53 & 0.154 & $14 \cdot 2$ \\
$3-5$ & 1.03 & 0.305 & $25 \cdot 2$ \\
$6-8$ & 1.41 & 0.384 & 27.8 \\
$9-11$ & 2.36 & 0.586 & 42.4 \\
$12+$ & 2.73 & 0.642 & 43.7 \\
\hline
\end{tabular}

in the highest stratum was more than four times the mean number in the lowest point group. The proportion of drivers with at least one collision in the $2 \frac{1}{2}$-year period tripled between the lowest and highest strata. These differences seem striking; however the drivers in each stratum differed substantially in traits known to be related to risk of accidents (Brezina, 1969). As demonstrated in Table III, drivers in the high-point strata were younger, more often male, and more likely to have a chauffeur's licence compared with drivers in the low-point strata. The value of points as an indicator of accident or conviction risk will be evident only when the confounding effects of these factors have been taken into account.

The collision risks for male drivers in each stratum, standardized for differences in age distribution, are shown in Table IV. The increasing risk with increasing demerit points is weaker after age adjustments have been made, but the risk for drivers with nine or more points remains more than double that of drivers in the $0-2$ point group. Also shown in Table IV are the age-standardized rates of collision for male drivers by class of licence. Standardization was required as there were substantial differences in the age and sex distribution of drivers who had an operator's or chauffeur's licence; the latter is required if the driver receives payment
TABLE IV

COLLISION RISKS BY CLASS OF LICENCE MALE DRIVERS, AGE-STANDARDIZED

\begin{tabular}{c|c|c|c}
\hline \multirow{2}{*}{$\begin{array}{c}\text { Demerit } \\
\text { Point } \\
\text { Stratum }\end{array}$} & \multicolumn{2}{|c|}{ Class of Licence } & \\
\cline { 2 - 4 } & $\begin{array}{c}\text { Operator } \\
\%\end{array}$ & $\begin{array}{c}\text { Chauffeur } \\
\%\end{array}$ & $\begin{array}{c}\text { Total } \\
\%\end{array}$ \\
\hline $0-2$ & $17 \cdot 0$ & $20 \cdot 5$ & $19 \cdot 0$ \\
$3-5$ & $26 \cdot 7$ & $35 \cdot 4$ & $31 \cdot 2$ \\
$6-8$ & $24 \cdot 9$ & $30 \cdot 5$ & $28 \cdot 7$ \\
$9-11$ & $41 \cdot 1$ & $42 \cdot 2$ & $42 \cdot 0$ \\
$12+$ & $37 \cdot 6$ & $44 \cdot 4$ & $43 \cdot 9$ \\
\hline
\end{tabular}

for driving. Young men (under 25 years) are more likely to possess a chauffeur's licence than older men or women of any age. In each demerit point stratum drivers with a chauffeur's licence have a higher risk of collision than drivers with an operator's licence, even after the rates have been standardized for age. In some strata, notably the 3-5 point group, thळ difference in risk is substantial.

Age standardization removes the effects $\vec{R} \otimes$ differences in age from comparisons of othe variables; to study the effects of age explicitly examined both the frequency of conviction fos $\frac{\mathbb{D}}{2}$ traffic offences and the risk of collision in mato $\vec{\varphi}$ drivers by age and demerit point group. The. of results are illustrated in Figs 1 and 2 . Tho data in Fig. 1 indicate that age and demerit points influence the frequency of conviction independently. Among drivers with a given level of points in July 1970, younger drivers accumulated more convictions in the following $2 \frac{1}{2}$ years than did older drivers. In each age group, drivers with more points in July 1970 tended to acquire more convictions subsequently.

For collisions (Fig. 2) the relationships are different from those for traffic convictions. Drivers with $0-2$ points had approximately the same risk

TABLE III

DRIVERS IN EACH DEMERIT POINT STRATUM AGE, SEX, AND CLASS OF LICENCE, JULY 1970

\begin{tabular}{|c|c|c|c|c|c|}
\hline \multirow[b]{2}{*}{ Stratum } & \multicolumn{3}{|c|}{ Age Quartiles (years) } & \multirow{2}{*}{$\begin{array}{c}\text { Sex } \\
\text { (Percentage of } \\
\text { Men) }\end{array}$} & \multirow{2}{*}{$\begin{array}{l}\text { Class of Licence } \\
\text { (Percentage with Chauffeur's Licence) }\end{array}$} \\
\hline & $25 \%$ & $50 \%$ & $75 \%$ & & \\
\hline $0-2$ & $23 \cdot 8$ & $34 \cdot 6$ & $46 \cdot 7$ & $58 \cdot 7$ & $33 \cdot 2$ \\
\hline $3-5$ & $25 \cdot 6$ & $34 \cdot 7$ & $45 \cdot 9$ & $83 \cdot 8$ & $52 \cdot 0$ \\
\hline $6-8$ & $23 \cdot 1$ & $28 \cdot 4$ & $39 \cdot 5$ & $93 \cdot 7$ & $60 \cdot 7$ \\
\hline $9-11$ & $22 \cdot 6$ & $26 \cdot 0$ & $33 \cdot 7$ & $96 \cdot 9$ & $70 \cdot 8$ \\
\hline $12+$ & $21 \cdot 6$ & $24 \cdot 5$ & $29 \cdot 7$ & $98 \cdot 9$ & $74 \cdot 4$ \\
\hline
\end{tabular}




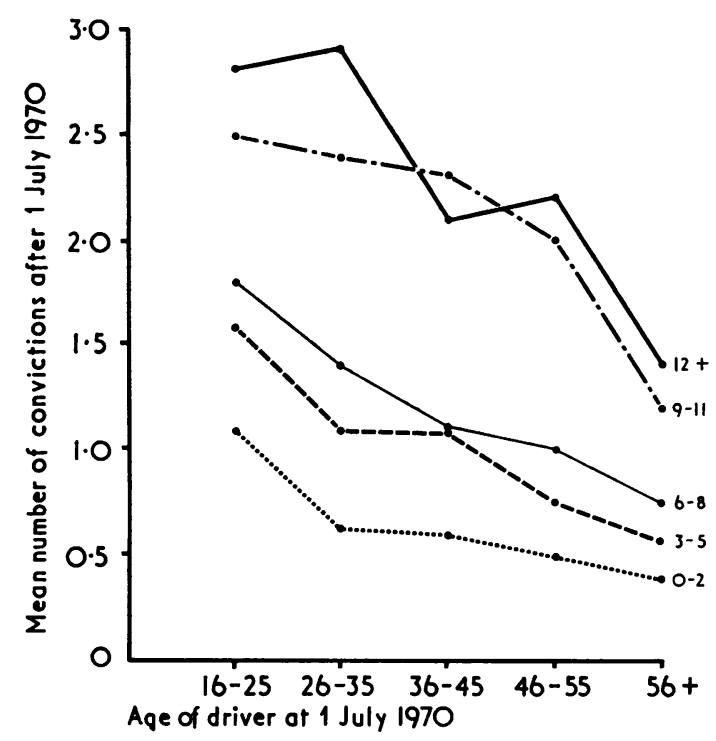

FIG. 1. Traffic convictions (men).

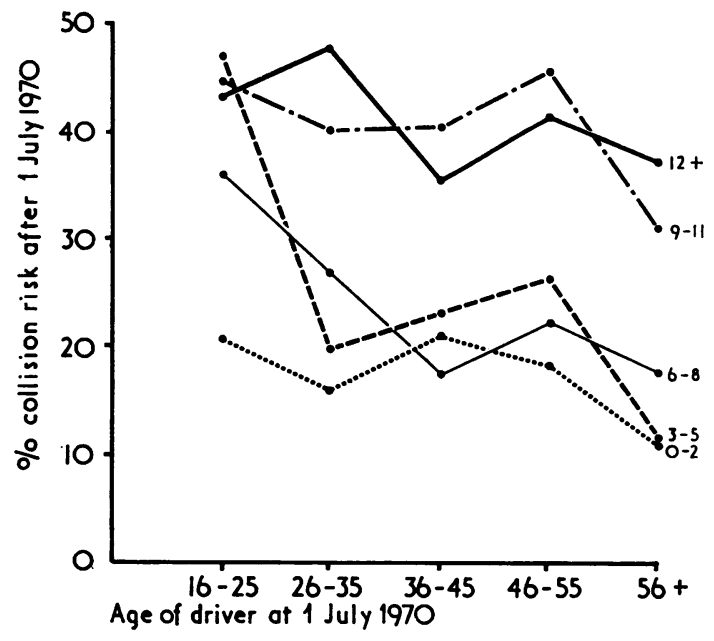

Fig. 2. Collision risk (men).

of collision (16-21\%) in each age group; drivers with nine or more points had much higher risks of collision (38-48\%) but again showed little difference with age. The collision risks by each age group were not statistically significant in these point strata, although the drop in risk of collision for older drivers (56+ years) was consistent for each stratum. However, collision risk varied considerably with the age of the driver in intermediate point groups. Drivers who were under 25 years of age and who had 3-5 points experienced a collision rate as high as any other group, and much higher than older drivers in the same point group. Among drivers with 6-8 points those aged under 25 years exhibited a similarly high rate of collisions compared with older drivers in that stratum. These differences in risk with age are each statistically significant at the $5 \%$ level.

These data concern only the men in the study; the rates for women demonstrated a similar pattern although the scarcity of women with more than six points made the data for these strata unreliable. In each age and demerit point group the rates of conviction and collision were much lower for women than for men.

The results of discriminant analysis in attempting to classify drivers into a 'conviction' and a 'no conviction' group are shown in Table V. In the $2 \frac{1}{2}$-year study period, $58 \cdot 5 \%$ of the drivers accumulated at least one traffic conviction. If drivers had been classified by a random method, one would expect to see approximately $58.5 \%$ of the drivers in the 'conviction' group and approximately $41.5 \%$ of the drivers in the 'no conviction' group correctly classified. When the drivers' demerit points were used, the proportion of drivers correctly classified rose to $77 \cdot 1 \%$ of the 'conviction' group and $56 \cdot 3 \%$ of the 'no conviction' group. Demerit points entered computations first because they appeared to have the greatest discriminating power; in fact, the addition of the remaining variablesimproved very slightly the proportion correctly identified in both groups. As shown in Table $\mathrm{V}$, the proportion in the "conviction' group classified correctly dropped by $2 \cdot 4$ percentage points.

In a similar fashion we studied the ability of these variables to classify drivers into those involved and not involved in any collisions during the study period. Results are presented in Table VI. Altogether $30.1 \%$ of drivers were actually involved in a collision, so that any random division of drivers into two groups should result in $30 \%$ of drivers correctly classified in the 'collision' group and $70 \%$

TABLE V

DRIVERS CORRECTLY IDENTIFIED IN CONVICTION AND NO-CONVICTION GROUPS

\begin{tabular}{|c|c|c|}
\hline \multirow[b]{2}{*}{$\begin{array}{l}\text { Discriminator } \\
\text { Variables }\end{array}$} & \multicolumn{2}{|c|}{ Percentage Correct } \\
\hline & $\begin{array}{c}\text { Conviction } \\
\text { Group }\end{array}$ & $\begin{array}{l}\text { No-conviction } \\
\text { Group }\end{array}$ \\
\hline $\begin{array}{l}\text { None (chance } \\
\text { allocation) }\end{array}$ & $58 \cdot 5$ & $41 \cdot 5$ \\
\hline Demerit points only & $77 \cdot 1$ & $56 \cdot 3$ \\
\hline All variables & $74 \cdot 7$ & $61 \cdot 9$ \\
\hline
\end{tabular}


TABLE VI

DRIVERS CORRECTLY IDENTIFIED IN COLLISION AND NO-COLLISION GROUPS

\begin{tabular}{|c|c|c|}
\hline \multirow[b]{2}{*}{$\begin{array}{l}\text { Discriminator } \\
\text { Variables }\end{array}$} & \multicolumn{2}{|c|}{ Percentage Correct } \\
\hline & $\begin{array}{l}\text { Collision } \\
\text { Group }\end{array}$ & $\begin{array}{l}\text { No-collision } \\
\text { Group }\end{array}$ \\
\hline $\begin{array}{l}\text { None (chance } \\
\text { allocation) }\end{array}$ & $30 \cdot 1$ & $69 \cdot 9$ \\
\hline Demerit points only & $41 \cdot 5$ & $78 \cdot 9$ \\
\hline All variables & $42 \cdot 6$ & $81 \cdot 2$ \\
\hline
\end{tabular}

of drivers correctly classified in the 'no collision' group. The use of demerit points as a discriminating variable improves the percentage of correct classifications to $41.5 \%$ and $78.9 \%$ respectively; the addition of the remaining variables considered in the analysis raised the percentages to $42.6 \%$ in the 'collision' group and to $81 \cdot 2 \%$ in the 'no-collision' group.

A total of 1105 collisions occurred to the drivers in the study. These collisions were classified as property damage only $(65.5 \%)$, or personal injury or fatality $(34 \cdot 5 \%)$. Discriminant analysis was of little or no value in classifying each collision as one with property damage only or involving personal injury and fatality. The results are given in Table VII. Classification of these collisions was very slightly improved over purely random allocation to $37 \cdot 2 \%$ using the entire array of discriminator variables. Demerit points entered as a discriminator only after class of licence and age of driver.

TABLE VII

COLLISIONS CORRECTLY IDENTIFIED BY OUTCOME

\begin{tabular}{cc|c|c}
\hline \multirow{2}{*}{$\begin{array}{c}\text { Discriminator } \\
\text { Variables }\end{array}$} & \begin{tabular}{c} 
Percentage Correct \\
\cline { 2 - 3 }
\end{tabular} & $\begin{array}{c}\text { Personal Injury } \\
\text { or Fatality }\end{array}$ & $\begin{array}{c}\text { Property Damage } \\
\text { only }\end{array}$ \\
\hline $\begin{array}{c}\text { None (chance } \\
\text { allocation) }\end{array}$ &. & $34 \cdot 6$ & $65 \cdot 4$ \\
All variables &. & $37 \cdot 2$ & $67 \cdot 8$ \\
\hline
\end{tabular}

\section{Discussion}

Demerit points are a measure of vulnerability to both collisions and traffic convictions in the future; this characteristic of drivers appears to be more sensitive than traits traditionally used to predict risk of accident such as age, sex, class of licence, and history of previous collisions. This is so whether one tries to measure the risk of involvement directly through the calculation of rates or to discriminate between drivers involved in and drivers free of collisions or traffic convictions.
There was no attempt at this stage to study the role of specific types of violation and their relationship to later behaviour. Many specific violations occurred too rarely to give reliable evidence of any association if considered alone. The demerit point score may comprise a few violations with many points (for example, careless driving, travelling more than $30 \mathrm{mph}$ above posted limit) or many violations with few points (for example, unnecessarily slow driving, improper right turn). More than half of the violations among the records in the study were for speeding; an earlier study (Brezina, 1969) found that speeding offences were more closely associated with subsequent collisions than other violations he considered.

There is undoubtedly substantial variation in the exposure of drivers in this study to the risk of collision or conviction: this is a variable which it was impossible to measure from the data available to us. Differences in the number of kilometres driven and the type of driving may explain a large part of the differences between men and womenand some of the differences between operator and chauffeur licences. 'Chauffeurs' may have a much more variable exposure than 'operators', since the former class includes all those who drive for a living (whether long-distance lorry drivers or drivers ob taxis and delivery vans) as well as many who drive only for personal use.

It is possible that the greater risk of demerif points, collisions, and convictions in younger drivers is due simply to greater exposure. However, Campbell (1972) conducted a survey of young drivers (16-25 years) in British Columbia who had had an accident and contrasted them with drivers of the same sex but who were 26 years older, and found that the young men drove slightly less than their older controls. Furthermore, he found that the frequency of traffic conviction per person per kilometre was substantially higher for young male drivers aged 20-25 years, but slightly lower for those aged 16-19 years when compared with their older controls.

The inconsistency of the association between age and the risk of collision involvement was unexpected. Collision rates for men showed little change with age in most demerit point strata; the exceptions were drivers with $3-5$ points and 6-8 points. It may be that driver control programmesinvolving interviews, retraining, and retesting of drivers with poor records-begin too late to be effective among young drivers. Although a warning letter is sent to each driver attaining six points, no attempt is made to alter driving behaviour until nine points have been assigned. In this stratum, 
the collision rate for drivers of all ages is at least double that for drivers with no points. Among drivers under 25 years, we have evidence that collision risk is substantially higher when only 3-5 points are earned, and intervention programmes might be more effective if they were begun at lower point levels for these drivers.

Demerit points are one variable the driver can control; he cannot alter his sex, exaggerate his age, or erase the occurrence of earlier accidents. For younger male drivers especially, this concept of control is important. A young man who is able to avoid demerit points and remain in the lowest point stratum appears able to avoid future collisions as successfully as older drivers in that stratum. This information may prove to be a valuable incentive, especially if it is reflected in the insurance rates he must pay. The fact that men under 25 years old had a higher frequency of traffic conviction, and hence were less likely to remain free of demerit points, suggests that such an incentive is badly needed.

The authors wish to thank Chris Young for computer programming, Elizabeth Andrushko and Irene Singer for clerical assistance, and officials of the Ministry of Transportation and Communication (Province of Ontario) for assistance with the collection of data.
Requests for reprints: Professor M. L. Chipman, Department of Preventive Medicine and Biostatistics, University of Toronto, Toronto, Canada.

\section{REFERENCES}

Baker, J. P., Robertson, L. S., and O'Neill, B. (1974). Fatal pedestrian collisions: driver negligence. Amer. J. publ. Hlth, 64, 318.

BrezinA, E. H. (1969). Traffic accidents and offences: an observational study of the Ontario driver population. Accid. Anal. and Prev., 1, 373.

CAMPBell, E. O'F. (Nov.-Dec. 1972). Investigation of exposure to risk factors among young drivers (16-25 years) 1969-71. Canad. J. publ. Hlth, 63, 504.

Dixon, W. J. ed. (1973). BMD Biomedical Computer Programs, 233, University of California Press, Berkeley and Los Angeles, California.

Fergenson, P. E. (1971). The relationship between information processing and driving accident and violation record. Hum. Factors, 13, 173.

Schmidt, C. W., Perlin, S., Townes, W., Fisher, R. S., and SCHAFFER, J. W. (1972). Characteristics of drivers involved in single-car accidents. Arch. gen. psychiat., 27, 800.

ZYLman, R. (1972). Drivers records: Are they a valid measure of driving behaviour? Accid. Anal. and Prev., 4, 333. 